\title{
CLIMA ORGANIZACIONAL: UMA ABORDAGEM PERCEPTIVA ENTRE GESTORES E COLABORADORES
}

ORGANIZATIONAL CLIMATE:AN APPROACH PERCEPTUAL BETWEEN MANAGERS AND EMPLOYEES

Lucas Almeida dos Santos', Edvir Schio², Leticia Lemos ${ }^{3}$, Vânia Medianeira Flores Costa ${ }^{4}$

RECEBIDO: 09/01/2018 | 12/04/2018

DOI: $10.5902 / 2317175830768$

\section{RESUMO}

Estudar o clima organizacional tem propiciado às organizações a identificação de elementos que afetam o comportamento dos colaboradores a partir de suas percepções e atitudes. O presente estudo, realizado numa empresa do ramo automotivo da região central do Rio Grande do Sul, possui como objetivo analisar o clima organizacional por meio das percepções dos gestores e colaboradores. Metodologicamente, esta pesquisa apresenta-se como um estudo de caso de natureza qualitativa e quantitativa, na qual a coleta de dados se deu por meio de entrevistas com os gestores e a aplicação de um questionário para os colaboradores. Como principais resultados, identificaramse algumas discordâncias mediante as percepções colocadas pelos envolvidos, bem como um desconhecimento, por parte dos gestores, acerca da realidade vivenciada no âmbito organizacional. Como sugestão, tem-se a criação de um setor voltado para atividades que promovam a integração de todos os envolvidos, auxiliando assim, na eficácia da gestão e melhoria do clima organizacional.

Palavras-Chave: Clima Organizacional; Relações Interpessoais; Desempenho Organizacional; Comportamento.

\footnotetext{
'Doutorando em Administração - UFSM; Graduado em Administração, Ciências Contábeis e Docência; Professor da Graduação e Pós Graduação.

2Edvir Schio, Bacharela em Administração de Empresas e graduanda em Ciências Contábeis pela Universidade Franciscana - UFN.

3 Graduanda em Ciências Contábeis pela Universidade Franciscana - UFN

${ }^{4}$ Professora do Centro de Ciências Sociais e Humanas - UFSM
} 


\begin{abstract}
Study the organizational climate has allowed organizations to identify elements that affect the behavior of employees from their perceptions and attitudes. This study in a automotive company aims to analyze the organizational climate through the perceptions of managers and employees. Methodologically, this research is presented as a case study of qualitative and quantitative where the data collection was carried out through interviews with managers and applying a questionnaire for employees. The main results, it identified some disagreements by perceptions placed by those involved as well as an ignorance on the part of managers, about the reality experienced in the organizational context. As a suggestion is the creation of a targeted sector for activities that promote the integration of all involved, thus helping in the effective management and improving the organizational climate
\end{abstract}

Keywords: Organizational Climate; Interpersonal Relations; Organizational Performance; Behavior.

\title{
1 Introdução
}

Toda organização possui, em seu ambiente interno, aspectos relativos ao comportamento humano, que frequentemente é mensurado para diagnosticar o clima organizacional de uma empresa, objetivando com isso o conhecimento da situação atual e o dimensionamento do nível de comprometimento e de satisfação dos funcionários.

É por meio das organizações que o colaborador satisfaz à maioria de suas necessidades, assim, as mesmas exercem certa influência em sua vida, desenvolvendo relações significativas, sejam individuais ou em grupo. Assim, essas experiências se expandem diariamente, trabalhando com diferentes comportamentos, levando e trazendo emoções, motivações e contribuindo para os planos futuros.

Em ambientes considerados competitivos, o valor das empresas não é medido apenas em termos de seus resultados econômicos ou financeiros, mas também em termos de sua imagem, da reputação e da capacidade de reter recursos humanos altamente qualificados (MORONI; DABOS, 2014). Tanto a literatura acadêmica quanto a prática gerencial mostram uma crescente preocupação com o clima organizacional como um meio para entender os fatores que afetam a confiança, comprometimento e desempenho dos colaboradores (CALDERON NARANJO E ALVAREZ, 2007; GUILLEN E ADUNA, 2008; LUTHANS, NORMAN, E AVEY AVOLIO, 2008).

$O$ estudo do clima organizacional tem atraído o interesse de muitos pesquisadores desde o último século (SCHNEIDER; EHRHART; MACEY, 2011; GUILLEN, 2013), principalmente, analisando a influência das mudanças tecnológicas, econômicas e sociais ocorridas nas organizações modernas. Seu estudo é de vital importância devido ao enorme impacto que tem sobre o comportamento dos membros de uma organização (PÉREZ; MALDONADO; BUSTAMANTE, 2006; NORIEGA, 2009), constituindo uma espécie de reflexo 
da vida da organização e as condições em que os trabalhadores operam no campo de trabalho (NORIEGA; PRIA, 2011).

Um bom ambiente de trabalho, na concepção de Souza, et al. (2015), se faz com uma equipe motivada, boa qualidade de vida e uma liderança eficaz. Esses são alguns dos fatores capazes de tornar eficaz a produtividade de uma equipe, construindo um cenário mais dinâmico e propício ao aprendizado. Neste sentido, o autor supracitado elucida que a percepção da influência do clima nas atividades institucionais dos colaboradores deve ser reflexo das ações desenvolvidas pela administração, objetivando estreitar as relações da organização com as pessoas que a compõe, consideradas hoje em dia, parceiras do negócio, e não meros recursos empresariais.

Diante do exposto, o presente estudo, elaborado a partir de enlace entre teoria e prática, realizado numa empresa de médio porte do ramo automotivo da região central do RS e de atuação nacional, tem por objetivo analisar as percepções dos gestores e colaboradores do setor administrativo em relação ao clima organizacional, sendo esse setor, o responsável por gerir e controlar todas as demais áreas da empresa.

Ademais, justifica-se a presente pesquisa devido à importância do clima organizacional na performance das organizações e sua relevância para o crescimento e a sobrevivência no longo prazo. Assim, torna-se necessário que os gestores compreendam que os instrumentos de administração, as técnicas econômicas e contábeis, as tecnologias sofisticadas não são nada sem a existência de um clima social e humano propício à união, à colaboração e ao desempenho de ambas as partes.

\section{Clima organizacional: breve revisão teórica}

O clima organizacional pode ser definido como a percepção que os membros possuem acerca do ambiente de atuação e sua influência no comportamento das pessoas (REYES; ZAPATA, 2014), que por meio de análise e avaliação de fatores organizacionais podem ser determinadas algumas características como a motivação, a satisfação das necessidades pessoais e organizacionais, condições de trabalho, a produtividade, a competitividade, entre outros. Todos esses aspectos, conforme Lerri e Cruz (2014), configuram as percepções conscientes e compartilhadas da realidade.

Em outras palavras, Santana e Araújo (2007) elucidam que o clima organizacional pode ser definido como um conjunto de percepções, suas políticas, práticas e procedimentos que são compartilhados por seus membros ao redor do ambiente de trabalho. Os autores também o mencionam como a personalidade de uma organização, ao passo que as características pessoais de um indivíduo configuraram suas próprias características de personalidade.

Moos (1973) já considerava que o clima é um dos aspectos do ambiente ou do meio que é moldada por fatores psicossociais do grupo de trabalho. Hellriegel 
e Slocum (1974) sugerem que quando o tempo é analisado e medido individualmente tem a ver exclusivamente com o clima psicológico, e quando ele é abordado a partir da organização, refere-se ao clima organizacional.

Swift e Huang (2008) propuseram um modelo que explica os efeitos do contexto organizacional (práticas de recursos humanos e gestão de clima) e da natureza das relações entre colegas de trabalho em afinidade ao comportamento e à partilha de conhecimentos.

Em outro estudo, Li, Zhu e Luo (2010) apontaram a influência do clima organizacional em comportamento e conhecimento de repartição em uma organização no sul da China. Os autores propuseram um modelo de pesquisa sobre os fatores que influenciam o comportamento no intercâmbio de conhecimentos entre as empresas. Esse estudo empírico mostrou que os componentes que foram medidos (relação favorável à inovação e justiça) contribuíram significativamente para o comportamento de partilha de conhecimentos e os comportamentos de auto eficácia e expectativa.

Destaca-se também o estudo de Abzari e Abbasi (2011), no qual por meio de duas variáveis, estudou-se o efeito do clima organizacional nos componentes da teoria do comportamento planejado (TPB), com o objetivo de analisar o comportamento de compartilhamento de conhecimento entre os funcionários da Universidade de Isfahan.

Tormo e Osca (2011) realizaram uma pesquisa que pretendia analisar, de maneira exploratória, o papel de três antecedentes pessoais e organizacionais nas intenções de compartilhar conhecimento: suporte, clima e comprometimento com a organização. Particularmente o que foram estudados eram as relações diretas de clima (especificamente de dimensões de orientação de tarefas e de apoio à inovação) com base na partilha de conhecimentos. Os resultados mostraram que a orientação "tarefa" tem um efeito direto sobre as intenções de partilha de conhecimentos, por isso é entendido como uma preocupação partilhada para alcançar a qualidade no resultado de trabalho.

Em relação às dimensões do clima organizacional, Cardenas, Arciniegas e Barreira (2009) apontam que este pode ter sete variáveis. As seguintes dimensões possuem uma base teórica de um foco percentual, em que o clima é o resultado das variáveis individuais e implicações psicológicas do indivíduo (REYES; ZAPATA, 2014). Essas dimensões são: (a) estilo de direção, (b) crescimento pessoal, (c) modelo de gestão, (d) o nível de trabalho, (e) relações interpessoais, (f) comunicação organizacional, e (h) a imagem corporativa, conforme pode ser visualizado no Quadro 1. 
Quadro 1: Dimensões do clima organizacional

\begin{tabular}{|c|c|c|}
\hline AUTOR & DIMENSÃO & DESCRIÇÃO \\
\hline Argyle (1994) & $\begin{array}{l}\text { Relações } \\
\text { Interpessoais }\end{array}$ & $\begin{array}{l}\text { Percepção do ambiente de trabalho a partir das interações entre os indivíduos dentro da } \\
\text { organização. As relações interpessoais referem-se a situaçõos sociais que envolvem duas ou } \\
\text { mais pessoas. }\end{array}$ \\
\hline Ucymat (2001) & Nível de Trabalho & $\begin{array}{l}\text { Percepção de ajudantes em termos da quantidade de trabalho, a pressão para o } \\
\text { cumprimento de metas e objetivos, o tempo gasto e a probabilidade de atingir os objetivos } \\
\text { no prazo estabelecido. A noção de sobrecarga parece estar estreitamente relacionada com } \\
\text { o conceito de incompatibilidade entre o que é necessário de o trabalhador e o que ele ou } \\
\text { ela é capaz de alcançar. }\end{array}$ \\
\hline Vallejo (2004) & $\begin{array}{l}\text { Crescimento } \\
\text { Pessoal }\end{array}$ & $\begin{array}{l}\text { Refere-se à atualização do potencial humano (psicológica e espiritual) que uma pessoa } \\
\text { pode ir além de seu desenvolvimento natural em termos de idade. O crescimento pessoal e } \\
\text { individual permite aprender através de sua própria consciência, tirar proveito de suas próprias } \\
\text { habilidades de pensar, sentir e agir para usar o pensamento autônomo, livre arbítrio, e } \\
\text { governar uma liberdade responsável por ser seu próprio líder e tendo em saúde emocional. }\end{array}$ \\
\hline $\begin{array}{l}\text { Echevarría } \\
(2007)\end{array}$ & Modelo de Gestão & $\begin{array}{l}\text { Refere-se à percepção da estrutura organizacional e como seu design permite que um bom } \\
\text { ambiente de trabalho. }\end{array}$ \\
\hline Zutta (2008) & Direção Estilo & $\begin{array}{l}\text { Define-se como a percepção que têm ajudantes de seus gestores em termos de } \\
\text { flexibilidade e reconhecimento nos processos de comunicaçã̃o. O estilo de direção constitui } \\
\text { os gestores 'adotado forma de orientar e conduzir as ações da organização, criando } \\
\text { autoridade e confiabilidade, mostrando a capacidade de gestão, a consciência dos cidadãos } \\
\text { necessidades e os interessados na organização, compromisso com o controle e missão, } \\
\text { visão, planos e o cumprimento dos programas, bom tratamento aos funcionários públicos e } \\
\text { uma utilização transparente e eficaz dos recursos. }\end{array}$ \\
\hline Cardenas (2009) & $\begin{array}{l}\text { Comunicação } \\
\text { Organizacional }\end{array}$ & $\begin{array}{l}\text { Define-se como a percepção que se tem dos sistemas formais de comunicação. Além disso, } \\
\text { refere-se ao processo pelo qual, um indivíduo ou uma parte de um organismo fica em } \\
\text { contato com a outra parte da mesma. }\end{array}$ \\
\hline Ruperti (2009) & $\begin{array}{l}\text { Imagem } \\
\text { Corporativa }\end{array}$ & $\begin{array}{l}\text { Percepção do posicionamento da organização e o impacto subjetivo. A imagem corporativa } \\
\text { é a personalidade da organização; em outras palavras, o que o define é um elemento } \\
\text { definido de diferenciação e posicionamento. }\end{array}$ \\
\hline
\end{tabular}

As sete dimensões destacadas no Quadro 1 são utilizadas como instrumento para medição do clima organizacional, em que tem-se uma abordagem de cada uma propiciando o desenvolvimento individual e coletivo do colaborador.

\subsection{Relações interpessoais nas organizações}

Considerando que o indivíduo não se relaciona com o mundo físico e social como um simples observador, mas como um ator que participa, que toma partido e que se envolve, e que esse mesmo indivíduo permanece na organização porque deseja e não porque necessita (TAMAYO, 2005), pode-se dizer que é ele que influencia o ambiente e não o inverso.

Para Leitão, Fortunato e Freitas (2006), uma questão primordial na linha de arguição biológica é que seres humanos se tornam humanos a partir do convívio com os outros, das interações ocorridas em seu processo de socialização, ou seja, o indivíduo surge e se desenvolve a partir de relacionamentos. Os autores relatam que a importância dada às relações parte do pressuposto de que as necessidades e interesses das organizações são as necessidades e interesses dos indivíduos de forma coletiva. As emoções são primordialmente reações singulares ocasionadas por interações sociais e são vistas como fenômenos sociais. 
Ainda conforme os autores supracitados, constata-se que o relacionamento interpessoal é um tema relevante para a vida associada e as condições em que ocorrem, pois definem a forma de convivência entre os humanos, que são seres de relações, e destes com a natureza. Os desgastes interpessoais resultam em deterioração das relações sociais, inter e intraorganizacionais.

Para Bergamini (2006), as pessoas precisam se relacionar da maneira mais produtiva possível para alcançarem os objetivos comuns. Quando essa interação é alcançada, percebe-se a existência daquilo que muitos autores chamam de sinergia, em que o todo é mais que a simples soma das partes, ampliando assim, as forças individuais e obtendo-se maior eficácia do todo. A constituição de redes nas organizações, conforme Tomaél, Alcará e Di Chiara (2005), ocorre por variadas formas e meios, desde uma conversa informal na hora de descanso até situações formalmente criadas, com a finalidade de alcançar resultados específicos, bem como evitar desentendimentos.

Contudo, acerca das relações humanas, o conflito acaba sendo inevitável, como afirmam diversos autores, dentre os quais Carvalho (1998), Quinn et al. (2003), Motta (2004), Carvalhal, André Neto e Andrade (2006), Chrispino (2007) e Mclntyre (2007). Uma das características essenciais das organizações é a capacidades de unir pessoas diferentes, com experiências, personalidades e objetivos diversos, em torno de um objetivo comum, então é bastante natural que surjam conflitos de diferentes origens, tipos e magnitudes. Assim, foram desenvolvidas, ao longo do tempo, diversas formas de gerenciamento, com o intuito de auxiliar no melhor aproveitamento dos benefícios desse fenômeno ou a eliminá-lo quando representa um problema aos processos de gestão.

Para Carvalho e Vieira (2007), as estruturas organizacionais possibilitam o surgimento de situações conflitivas, pois são canais que permitem o exercício da autoridade e a realização do poder. Com base no exposto, é possível inferir que a configuração estrutural estabelecerá como essas relações entre os diversos indivíduos ocorrem, tendo base potencial para a existência de conflitos.

No âmbito das relações, de acordo com Madariaga (2010), há uma interdependência entre a comunicação e a liderança. Assim, é preciso que a integridade do líder favoreça o processo comunicacional organizacional, estruturando assim um contexto de confiança. Assim, Vendemiatti et al. (2010) enfatizam que a atuação da liderança deve ser orientada por processos de diálogo e negociação, no intuito de construir relações de confiança que permitam a atribuição de significado à ação dos liderados.

\subsection{Avaliação do clima organizacional frente ao desempenho dos colaboradores}

Avaliar o clima organizacional permite a identificação de uma série de elementos internos da instituição de formais (produto) e informal (processo), a fim de analisar como estas afetam o comportamento dos colaboradores, a partir de suas percepções e atitudes, e de como elas influenciam sua motivação (MÉNDEZ, 2006). 
Guillén, Gala e Velázquez (2000) explicam que, quando o ambiente institucional é explorado, a visão pode ser focada em qualquer um dos seguintes fatores: aspectos organizacionais, o indivíduo ou a interação pessoa / situação. Atualmente, essa abordagem vem progressivamente ampliando as percepções do que acontece no interior das instituições (SALAZAR et al, 2015), uma vez que sua abordagem não é simples, uma vez que cada organização possui suas peculiaridades.

Independentemente dos fatores que pretende-se explorar, a avaliação de clima organizacional nas instituições tem crescido rapidamente, sendo considerada como uma opção para alcançar a eficácia da gestão por meio da percepção dos colaboradores que, envolvidos nos processos, sofrem influência do ambiente de atuação (CHIANG; NÚÑEZ, 2005). Neste sentido, segundo Neves (2000), o clima influencia na motivação e comprometimento dos indivíduos, bem como em sua produtividade.

O clima organizacional, na concepção de Chambel e Curral (2008), tem um papel intermediário entre as características da organização e os resultados individuais, como as atitudes, a motivação e o desempenho dos colaboradores. Isso porque a percepção do contexto de trabalho, quando relacionada, evoca expectativas e valências, que têm uma influência direta na motivação, e desencadeia também sentimentos de satisfação e de identificação com o próprio trabalho e com o meio, como apresenta na Figura 1.

Figura 1 - Relação entre clima, atitudes e resultados.

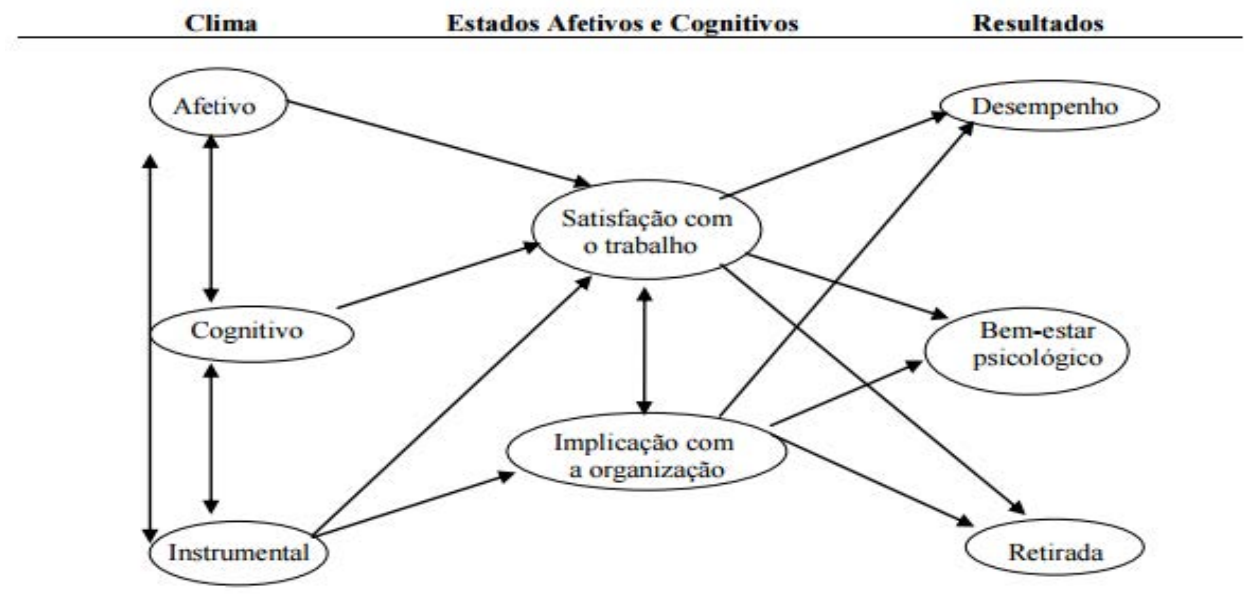

Fonte: Adaptado de Chambel e Curral (2008).

No que tange a literatura, alguns estudos foram elaborados levando em consideração os efeitos do clima organizacional no desempenho dos colaboradores. Kopelman et al. (1990) concluiu que as práticas de gestão de recursos humanos tinham um efeito direto no clima, e este por sua vez, influenciava a motivação, satisfação e o envolvimento dos indivíduos. Parker (2003), num estudo alargado em diferentes indústrias, chegou a conclusões semelhantes, verificando as relações 
fortes e diretas do clima com as atitudes, motivação e envolvimento, também verificou o impacto do clima no estado efetivo e cognitivo do indivíduo, os quais poderiam por sua vez influenciar os seus comportamentos.

A avaliação do clima pela própria equipe é uma forma que mensura o desempenho desta como um todo (BOHLANDER; SNELL, 2009). Para esses autores, isso é bastante utilizado quando se trata de trabalhos em grupo, no qual é difícil avaliar a contribuição individual. Ou seja, um aspecto positivo desse tipo de avaliação é que há um incentivo para o esforço coletivo, rompendo com possíveis barreiras entre os colegas de trabalho, podendo ser complementado pelo pagamento variável, de acordo com o desempenho do grupo.

Em outras palavras, o clima tem como base as percepções dos empregados sobre a qualidade do ambiente de trabalho interno, por isso caracteriza-se pela natureza da relação pessoal-organização e pela relação superior-subordinado (MULLINS, 2004). A avaliação do clima organizacional de qualquer empresa agora ou futuramente tem que ser uma realidade, na qual deve haver investigação, pesquisa e análise de resultados e, a partir daí, implementar e estabelecer as ações, que de tal forma, tornarão o ambiente mais motivador.

Diante do exposto, os gerentes são suscetíveis de serem partes interdependentes nas decisões e ações dos outros, se quiserem alcançar seus próprios objetivos (FAURÉ; ROULEAU, 2011), em consequência, podem também arbitrar objetivos orçamentais de acordo com seus próprios objetivos, tais como a qualidade do produto e a política de serviços (por meio da adoção de táticas discricionárias (OTLEY, 1978; ROBERTS, 1991; DAVILA; WOUTERS, 2005).

Em síntese, o clima organizacional faz menção às percepções que os colaboradores de uma organização têm sobre ela e seu ambiente de trabalho e nessa perspectiva, a satisfação seria uma causa provável de um melhor desempenho dos mesmos frente às atividades desenvolvidas (ROBBINS; JUDGE; SOBRAL, 2011). Por fim, destaca-se que os colaboradores estando satisfeitos tendem a falar bem da empresa, a contribuir com os colegas e a excederem as expectativas com relação ao trabalho, podendo também superar suas atribuições regulares pelo anseio de retribuir as expectativas positivas.

\section{Método de pesquisa}

Nesta pesquisa, utilizou-se as abordagens qualitativa e quantitativa, em que o método quantitativo está voltado para a mensuração dos fenômenos, envolvendo a coleta e análise de dados, bem como a aplicação de testes estatísticos na tabulação dos resultados. No método qualitativo, tem-se a relevância da realidade abordada e sua contribuição para o desenvolvimento do estudo, sendo esta, vista de forma mais subjetiva, uma vez que envolve uma reflexão e análise do contexto e percepções com o intuito de construir o conhecimento necessário, de forma não-mensurada das variáveis (COLLIS; HUSSEY, 2005; CAUCHICK MIGUEL, et al. 2012). 
Portanto, o presente estudo, desenvolvido numa empresa do ramo automotivo da região central do Rio Grande do Sul e atuante em nível nacional delineia-se a partir de um estudo de caso e tem como objetivo analisar as percepções dos gestores e colaboradores do setor administrativo em relação ao clima organizacional, sendo estes, responsáveis por gerir e controlar todas as demais áreas da empresa. Na Figura 2 visualiza-se, de forma macro, o delineamento da pesquisa realizada.

Figura 2: Delineamento da pesquisa

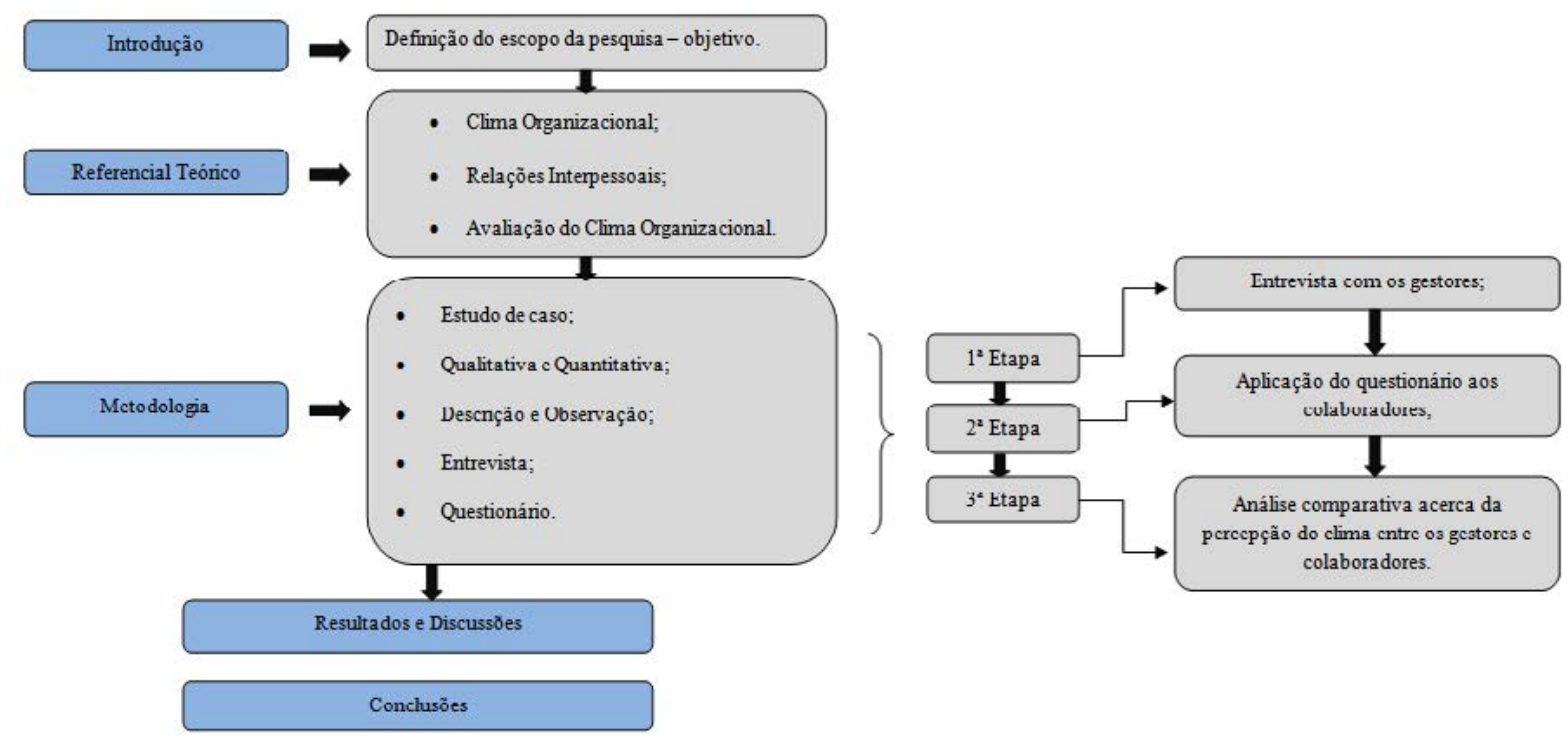

Fonte: Elaborado pelos autores

O instrumento utilizado na coleta de dados se deu a partir de uma entrevista semiestruturada realizada com os cinco diretores (Geral, Financeiro, Administrativo, TI, Recursos Humanos) - denominados para as análises como: G1, G2, G3, G4, G5 - com o intuito de responder o objetivo geral do presente estudo. Após a realização da entrevista com gestores foi adaptado, a partir de suas considerações, um questionário, que aplicado aos colaboradores possibilitou uma comparação entre as respostas. Para isso, a adaptação do questionário se deu por meio da escala Likert de cinco pontos, sendo 1- Discordo totalmente, 2- Discordo em maior parte, 3- Indiferente, 4 - Concordo em maior parte, 5-Concordo totalmente, pois esse tipo de escala não comparativa pode ter a descrição do grau adaptado, de acordo com a realidade pesquisada (COSTA, 2011; MALHOTRA, 2012). Ainda, salienta-se que o questionário foi desenvolvido pelos autores deste artigo com base na literatura apresentada e de acordo com o ambiente pesquisado, visto que, não foi possível adaptar ou utilizar uma escala pronta para a amostra abordada neste trabalho.

Mediante uma amostragem não convencional, dos 60 colaboradores do setor administrativo, 35 responderam o questionário, os quais puderam escolher entre as cinco alternativas da escala Likert a que melhor espelha a realidade em que estão envolvidos. Contudo, foram adicionadas, também, 
ao questionário, questões referentes ao perfil dos respondentes, como idade, gênero, tempo de empresa, grau de instrução e remuneração.

\section{Apresentação e discussão dos resultados}

Neste tópico são dispostos os resultados construídos a partir do levantamento de dados, que se deu por meio de um enlace entre a teoria e prática, contemplado no referencial, a entrevista com os gestores, e a aplicação dos questionários com os colaboradores.

A empresa foco deste estudo está voltada para prestação de serviços e venda de mercadorias do ramo automotivo, possuindo atuação nacional com expressiva participação de mercado. Desde seu surgimento, a organização que outrora comercializava apenas pneus, atualmente expandiu seu rol de atividades, passando também a oferecer serviços, que por meio de tecnologias de ponta, garantem a satisfação dos clientes e aumenta o seu desempenho organizacional. Atualmente, a empresa possui filiais espalhadas em sete estados brasileiros, sendo a administração das mesmas localizadas na região Central do Rio Grande do Sul, onde esta pesquisa foi desenvolvida. Dentre os seus clientes, encontram-se pessoas jurídicas, pessoas físicas e estabelecimentos parceiros, estes atuando na prestação de serviços em cidades estratégicas dos estados atuantes.

No que tange a sua estrutura organizacional a mesma encontra-se dividida em setores, facilitando, assim, a gestão do negócio. Para cada setor, há um gerente responsável, que permanecendo na matriz coordena os demais gestores que permanecem dentro das filiais. Dessa forma, todos os gerentes são responsáveis por gerir os recursos materiais e humanos de cada setor e reportam-se ao diretor geral e demais acionistas.

\subsection{Perfil dos colaboradores}

Este tópico aborda o perfil dos colaboradores participantes, que auxiliam os gestores na administração da organização, desempenhando funções desde o controle, até a execução dos procedimentos. Na Figura 3 verifica-se as questões referentes ao gênero, idade, tempo de empresa, remuneração e grau de instrução dos colaboradores. 
Figura 3: Perfil dos colaboradores setor administrativo

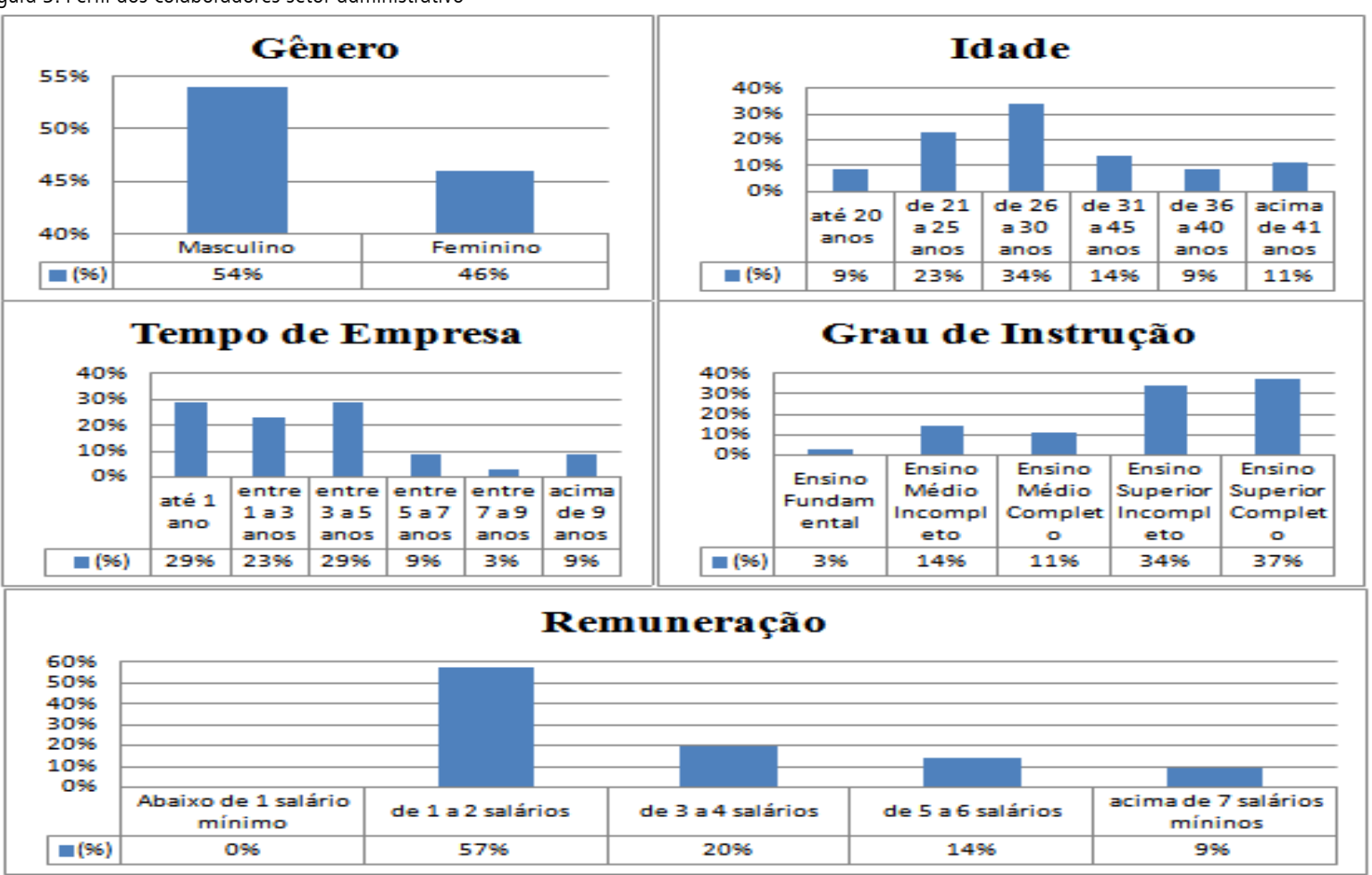

De acordo com as respostas obtidas, percebe-se que $54 \%$ dos entrevistados são do sexo masculino e $46 \%$ feminino, sendo $34 \%$ com idade entre 26 e 30 anos. Quanto ao tempo de trabalho desempenhado na empresa, a maioria possui até 7 anos, $57 \%$ ganham de 1 a 2 salários mínimos, e na sua totalidade, $71 \%$ possuem superior completo ou incompleto. Assim, entendese que a organização, na sua maioria, apresenta colaboradores jovens e com pouco tempo de empresa. Na concepção de Jaramillo (2013), esses aspectos, quando observados comparativamente, permitem identificar e criar um perfil que contribui na construção de uma cultura organizacional.

4.2 Análise do clima organizacional: percepção dos gestores

A avaliação do clima organizacional segue as etapas descritas na metodologia (Figura 2), primeiramente foi feito uma entrevista com os gestores da empresa, responsáveis por gerir o negócio. Num segundo momento, a partir de suas percepções acerca do clima, foi adaptado e aplicado um questionário aos colaboradores do setor administrativo, possibilitando assim, uma análise das falas dos gestores e a realidade vivida pelos funcionários.

Com isso, no Quadro 2 apresenta-se as percepções dos gestores acerca da realidade da organização, das quais foi adaptado um questionário e aplicado aos colaboradores. Para o levantamento dessas questões, foi solicitado aos mesmos que comentassem sobre as questões mais relevantes quanto ao clima organizacional, tendo os mesmos, total liberdade de mencionar o que desejassem. 
Quadro 2. Respostas dos gestores

\begin{tabular}{|l|l|l|}
\hline & SínTESES DAS PERCEPÇÕES DOS GESTORES & $\mathrm{GESTORES}$ \\
\hline 1 & Considero a empresa um ótimo lugar para se trabalhar. & $\mathrm{G} 1, \mathrm{G} 2, \mathrm{G} 3, \mathrm{G} 4$ e G5 \\
\hline 2 & Julgo ser importante o trabalho que os colaboradores realizam. & $\mathrm{G} 2, \mathrm{G} 3$ e G5 \\
\hline 3 & Considero que todos estão satisfeitos com o trabalho que realizam. & $\mathrm{G} 1$ e G5 \\
\hline 4 & $\begin{array}{l}\text { Considero que todos os funcionários são tratados com respeito entre os membros da equipe } \\
\text { independente dos seus cargos. }\end{array}$ & $\mathrm{G} 1$ e G2 \\
\hline 5 & O clima de trabalho entre a equipe é bom dentro da organização. & $\mathrm{G} 1, \mathrm{G} 2, \mathrm{G} 3, \mathrm{G} 4$ e G5 \\
\hline 6 & Os colaboradores são bem integrados e ajudam-se mutuamente. & $\mathrm{G} 1, \mathrm{G} 3$ e G5 \\
\hline 7 & $\begin{array}{l}\text { Existe um bom relacionamento entre os membros do grupo de trabalho, tanto pessoal como } \\
\text { profissional. }\end{array}$ & $\mathrm{G} 1, \mathrm{G} 2$ e G3 \\
\hline 8 & A organização é aberta a receber e reconhecer as opiniões e contribuições dos colaboradores. & $\mathrm{G} 1, \mathrm{G} 2, \mathrm{G} 3$, e G5 \\
\hline 9 & Existe liberdade para opinar sobre o trabalho realizado. & $\mathrm{G} 1$ e G5 \\
\hline 10 & $\begin{array}{l}\text { Os membros participam juntamente com seu superior e com a equipe das decisões que afetam o } \\
\text { trabalho. }\end{array}$ & $\mathrm{G} 4$ \\
\hline 11 & A remuneração está de acordo com a praticada no mercado. & $\mathrm{G} 1$ \\
\hline 12 & O trabalho executado pelos colaboradores faz com que se sintam bem profissionalmente. & $\mathrm{G} 1, \mathrm{G} 2, \mathrm{G} 3, \mathrm{G} 4$ e G5 \\
\hline 13 & Os colaboradores executam suas tarefas diárias no horário normal de trabalho. & $\mathrm{G} 1, \mathrm{G} 2, \mathrm{G} 3$, e G5 \\
\hline 14 & Há oportunidade de desenvolvimento dentro da empresa. & $\mathrm{G} 1$ e G4 \\
\hline 15 & $\begin{array}{l}\text { Os colaboradores participam frequentemente das atividades de integração promovidas dentro da } \\
\text { organização }\end{array}$ & $\mathrm{G} 1$ e G5 \\
\hline 16 & $\begin{array}{l}\text { A remuneração de cada colaborador é compatível com as responsabilidades inerentes ao trabalho } \\
\text { que realiza. }\end{array}$ & $\mathrm{G} 1$ e G5 \\
\hline 17 & Existem políticas de treinamentos e aperfeiçoamento dos funcionários. & $\mathrm{G} 1, \mathrm{G} 2, \mathrm{G} 3, \mathrm{G} 4$ e G5 \\
\hline Fonte: Elaborado pelos autores & \\
\hline
\end{tabular}

Ademais, percebe-se que as afirmativas apontadas pelos gestores envolvem a organização como todo, permeando desde a satisfação dos colaboradores, quanto à participação dos mesmos nos processos decisórios. A contextualização exposta revela, também, a percepção que os mesmos possuem diante de questões comportamentais de seus subordinados, sendo estes, responsáveis pela liderança e implantação de práticas que sustentam e mantenham um bom clima entre os envolvidos.

Outra característica marcante percebida nas arguições dos gestores é a constante afirmação de um trabalho coeso entre os colaboradores, em que os mesmos apontam a formação de uma equipe com um bom nível de relacionamento, ratificando assim, a participação de todos no processo decisório, satisfação com o trabalho realizado, boa comunicação organizacional, crescimento pessoal e profissional, remuneração compatível com as funções, além do aperfeiçoamento mediante cursos e treinamentos.

Assim, ratificando o resultado encontrado com a literatura abordada, torna-se importante destacar que o estudo de clima organizacional (FERREIRA et al.; 2006) está intimamente ligado com as influências de crenças, valores e cultura dos indivíduos que orientam as relações entre os colaboradores quanto à prestação de serviços na organização, determinando o que é bom ou ruim para eles e para a empresa como um todo. 
4.3 Análise do clima organizacional: percepção dos colaboradores

Esta seção apresenta a segunda e terceira etapa da pesquisa, no qual a partir das afirmativas dos gestores elaborou-se um questionário para ser aplicado aos colaboradores, que puderam apontar sua concordância ou discordância acerca das assertivas apresentadas. Com isso, os mesmos não tinham conhecimento de que as questões estavam embasadas nos apontamentos feitos pelos dirigentes da organização, evitando assim distorções nas respostas.

Realizar pesquisas com os colaboradores da empresa, em busca de avaliar o seu perfil em relação ao seu grau de motivação, satisfação e de integração, pode trazer resultados de melhorias, o que resulta na entrega de produtos e serviços de qualidade (FERREIRA et. al., 2006). Na Figura 4, os participantes deram seu parecer acerca da seguinte assertiva: considero a empresa um ótimo lugar para se trabalhar.

Figura 4 - Considero a empresa um ótimo lugar para se trabalhar

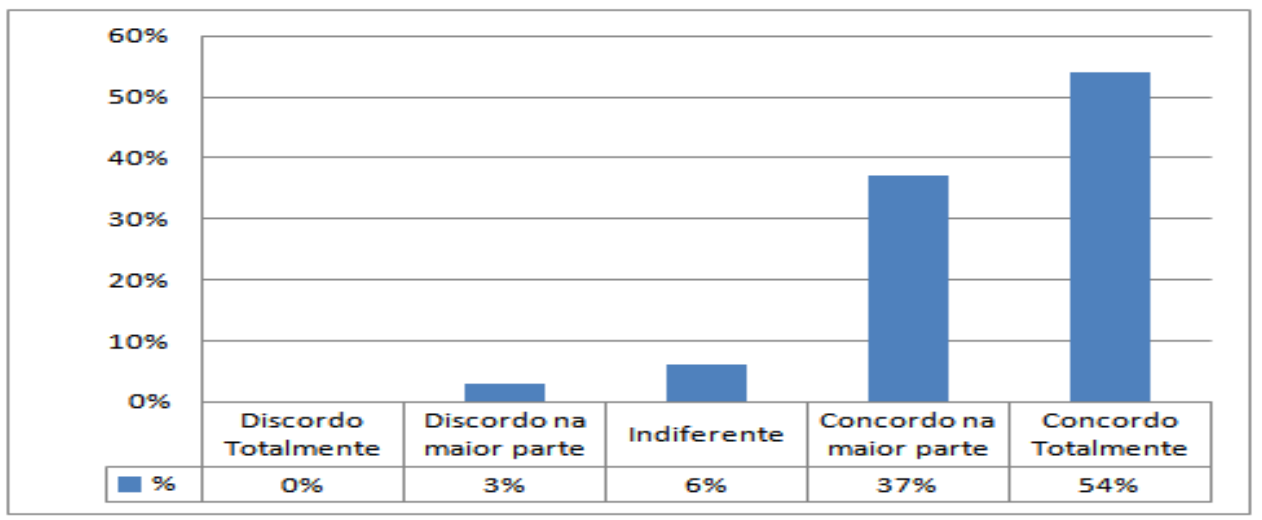

A maioria dos respondentes, ou seja, 54\% alegaram concordar totalmente com os gestores e consideram a organização um ótimo lugar para se trabalhar, enquanto $3 \%$ apontaram que discordam na maior parte com o que foi apresentado. Essa situação pode prejudicar o trabalho em equipe e influenciar negativamente o clima organizacional, pois ele nunca é claramente definido, sendo difuso e incorpóreo, e se manifesta no dia-a-dia da organização como uma espécie de fantasma, numa associação de ações, reações e de sentimentos nunca explicitados (FERREIRA, et al., 2006).

Quanto à assertiva elucidada pelos gestores acerca da importância do trabalho realizado pelos colaboradores, é necessário que todos os envolvidos nas atividades organizacionais sintam-se valorizados, pois o seu desempenho e comprometimento satisfatório, também dependerá da forma como este se percebe importante frente às atividades realizadas. Na Figura 5, os participantes expuseram sua opinião acerca da seguinte questão: julgo ser importante o trabalho que realizo dentro da empresa. 
Figura 5 - Julgo ser importante o trabalho que realizo dentro da empresa

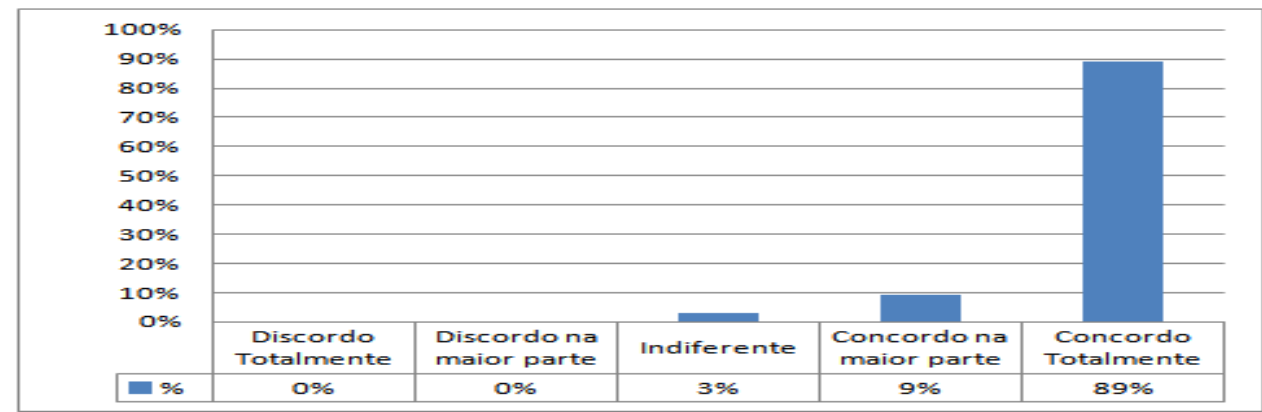

Na Figura 5, nota-se que $89 \%$ dos respondentes concordam totalmente quanto à importância de seu trabalho para a organização, enquanto $4 \%$ permanecem indiferentes. $O$ fato dos colaboradores perceberem $\circ$ quão importante é o seu trabalho para a organização, melhorará seu desempenho e comprometimento, pois isto aumenta a dedicação dos mesmos, tendo maior possibilidade de entregar bens e serviços que atendam as necessidades dos clientes de forma mais ágil e com qualidade (SILVA; MATSUDA e WAIDMAN, 2012).

Quanto à satisfação com o trabalho realizado, a mesma é o principal fator que gera impacto nas organizações, uma vez que as pessoas insatisfeitas e desmotivadas necessitam de algo que possam se estimular. Na Figura 6, os colaboradores expuseram sua satisfação quanto a seguinte proposição: considero-me satisfeito com o trabalho que realizo.

Figura - 6 Considero-me satisfeito com o trabalho que realizo.

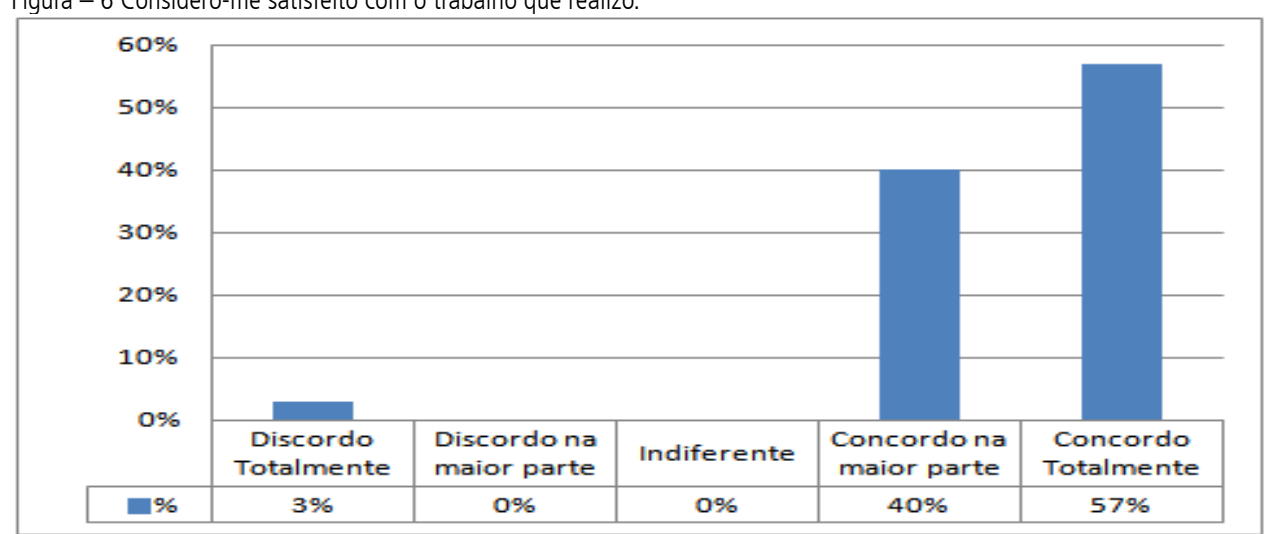

Com isso, percebe-se que $57 \%$ consideram-se totalmente satisfeito com o trabalho que realiza na organização e $3 \%$ totalmente insatisfeito, pois discordam totalmente com a afirmativa apontada pelos gestores. Assim, a satisfação dos funcionários é uma medida de quão felizes com seu trabalho no ambiente em que executam suas atividades (GOHEL, 2012).

Além de estarem satisfeitos, o tratamento dado às pessoas, independente do cargo ocupado, assegura uma harmonia no clima organizacional e motiva os colaboradores na busca por melhores resultados. Mediante o exposto, na 
Figura 7, tem-se a percepção dos envolvidos no que tange ao tratamento recebido, por parte dos gestores, dentro da organização.

Figura - 7 Todos os colaboradores são tratados com respeito independente de sua ocupação

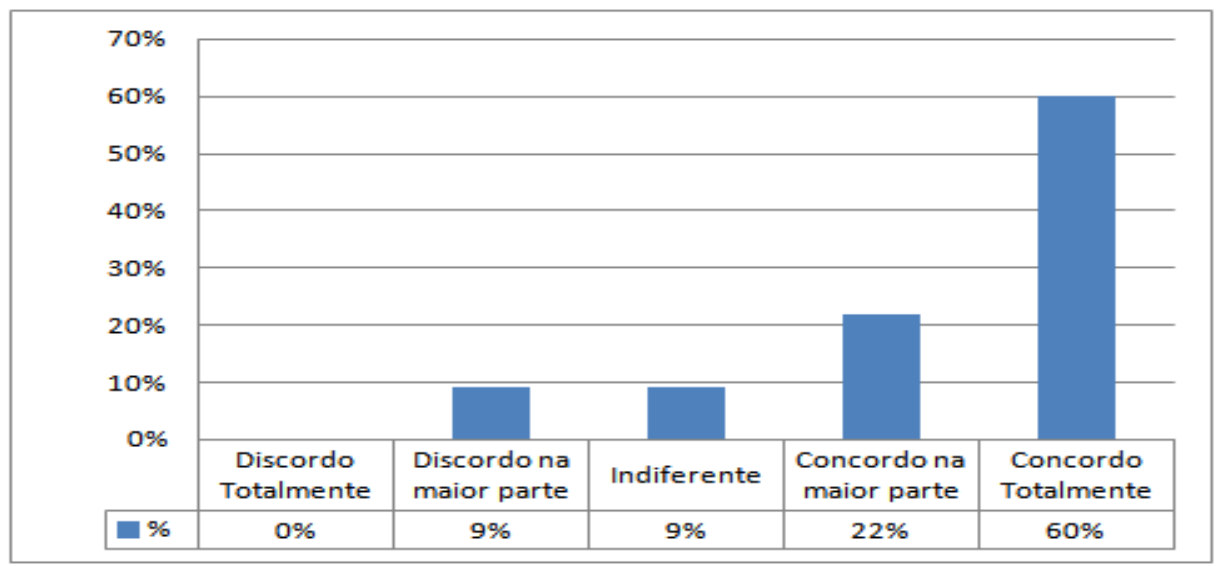

Neste aspecto, $60 \%$ dos respondentes concordam que são tratados com respeito e $9 \%$ discordam em partes quanto a essa questão, podendo intuir que estes não estão satisfeitos com o tratamento recebido por parte dos gestores. Tal assertiva que foi apontada, primeiramente pelos gestores, não está de comum acordo o que pode causar conflito e desestruturar o ambiente trabalho. Com isso, Carmeli; Durtton; Hardin (2015) salientam que um tratamento respeitoso entre os membros da organização facilita o processamento de informação relacional e promove o comportamento criativo, tanto a nível individual quanto de equipe.

O clima organizacional afeta diretamente todos os indivíduos e equipes do ambiente institucional, promovendo, quando este é favorável, a motivação e bem-estar dos envolvidos. Além disso, de acordo com Chiavenato (2010), um ambiente de trabalho agradável facilita o relacionamento interpessoal e melhora a produtividade, bem como reduz acidentes, doenças, absenteísmo e rotatividade de pessoal. Nesta perspectiva, foi solicitado aos colaboradores que avaliassem a assertiva colocada pelos gestores quanto ao clima de trabalho ser bom, conforme Figura 8. 
CLIMA ORGANIZACIONAL: UMA ABORDAGEM PERCEPTIVA ENTRE GESTORES E COLABORADORES

Figura 8 - Clima no ambiente de trabalho é bom entre os membros da equipe

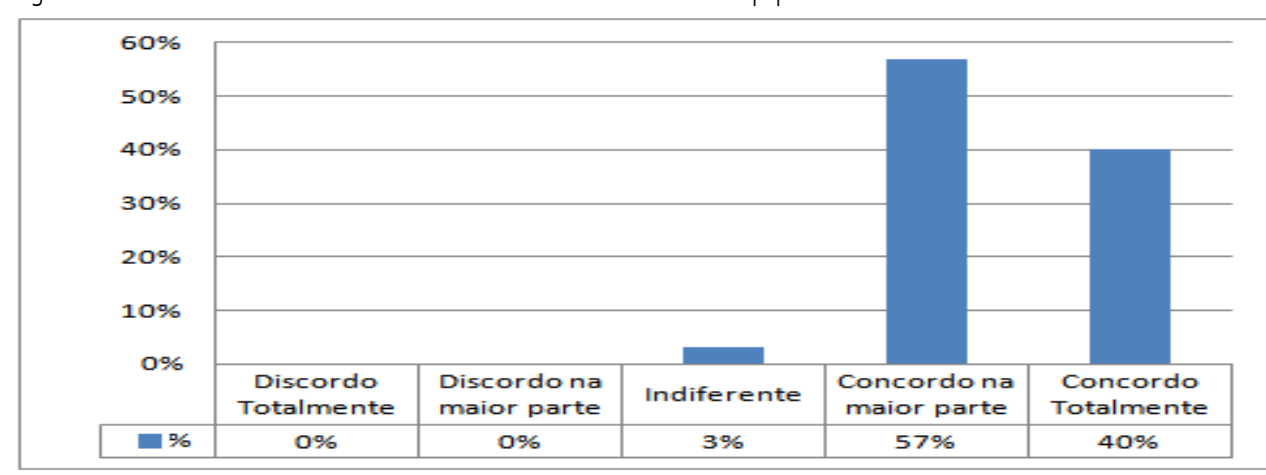

Analisando-se as respostas, percebe-se que $57 \%$ dos entrevistados concordam em maior parte que o clima no ambiente de trabalho é considerado bom, enquanto $3 \%$ permaneceram indiferentes quanto a este aspecto. Assim, intui-se que no geral o clima é considerado bom pelos colaboradores, que corroborado por Noriega (2011), o mesmo é considerado um filtro no qual passam os fenômenos objetivos de uma organização, que quando recebidos por membros individuais criam uma percepção de que influencia as suas motivações e comportamentos.

No ambiente de trabalho, vários são os fatores que contribuem para o aumento do comprometimento e produtividade dos indivíduos de uma equipe. A relação com os colegas de trabalho, por exemplo, favorece a construção de um clima solidificado em relações interpessoais que em muitos casos perpassam o profissional, entende-se também à vida pessoal de cada um. Dessa forma, os participantes opinaram quanto à integração existente entre os mesmos e se estes ajudam-se mutuamente, bem como se há um bom relacionamento entre os colaboradores dentro da organização, conforme Figura 9 (A e B).

Figura 9 - (A) Os colegas de trabalho são bem integrados e ajudam-se mutuamente - (B) Existe um bom relacionamento entre os membros do grupo de trabalho tanto pessoal como profissional.

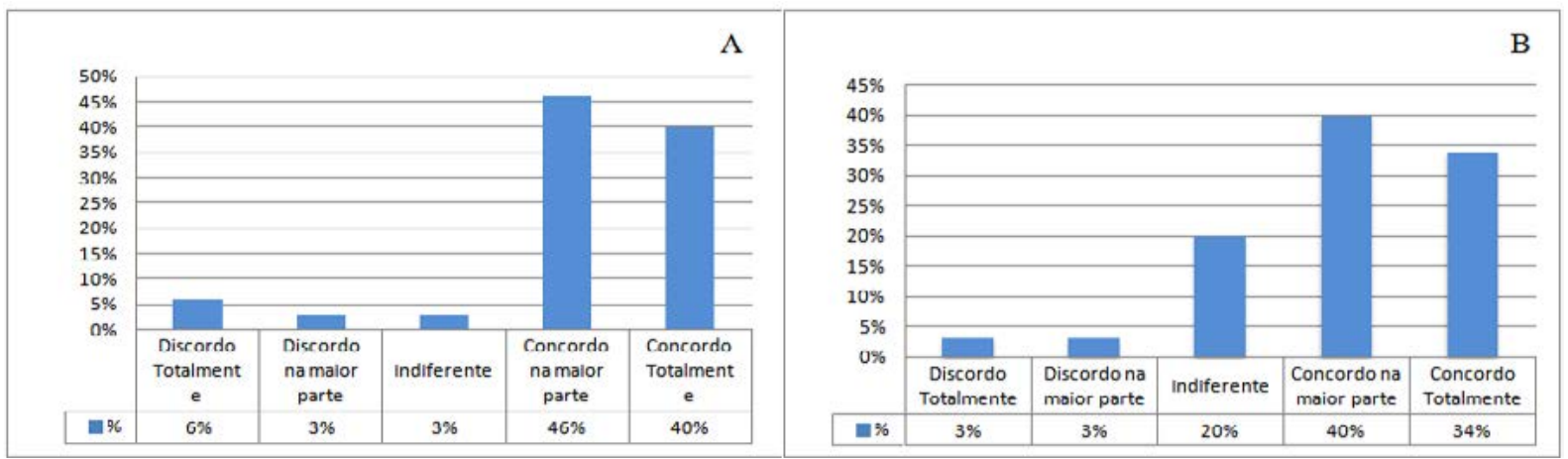


Por meio da Figura 9 (A), percebe-se que $46 \%$ dos respondentes concordam na maior parte quanto à integração entre os colegas de trabalho e que estes se ajudam mutuamente, enquanto $6 \%$ dos participantes discordam totalmente em relação a essa situação. Com isso, apesar da maioria concordar com a assertiva, os que se apresentaram contrário podem ser uma preocupação para a administração da empresa, influenciando negativamente no comportamento dos demais e prejudicando o clima organizacional.

Quanto à existência de um bom relacionamento entre os membros do grupo, tanto pessoal quanto profissional, conforme na Figura 9 (B), 40\% dos entrevistados concordam na maior parte no que tange a positividade do relacionamento, porém, $20 \%$ permaneceram indiferentes a respeito desta perspectiva. A imparcialidade, neste caso, pode estar atrelada ao medo de se expor, temendo a perda do emprego ou indisposição com os demais membros. Esse tipo de comportamento prejudica a avaliação e análise que se pretende acerca de uma problemática.

Complementando o exposto, Souza, Júnior e Magalhães (2015) elucidam que é de suma importância que em todas as organizações haja um ambiente de trabalho amistoso que proporcione trocas agradáveis, harmoniosas e sadias entre as pessoas, para que estas trabalhem satisfeitas e motivadas em busca do sucesso pessoal e organizacional.

Outro fator importante e que gera um impacto no clima organizacional é quanto à participação dos colaboradores no processo decisório e a liberdade de expressão, advindas de uma gestão democrática e participativa. Envolver os funcionários nas decisões faz com que os mesmos se percebam importantes, criando uma percepção acerca da valorização do trabalho prestado. Acerca do exposto, conforme na Figura 10, os participantes demarcaram sua opinião quanto à preparação da organização em receber e reconhecer suas opiniões, bem como quanto à existência de liberdade de opinar acerca de assuntos profissionais.

Figura 10 - (A) A organização é aberta a receber e reconhecer as opiniões e contribuições dos colaboradores - (B) Existe liberdade para opinar sobre o trabalho realizado.

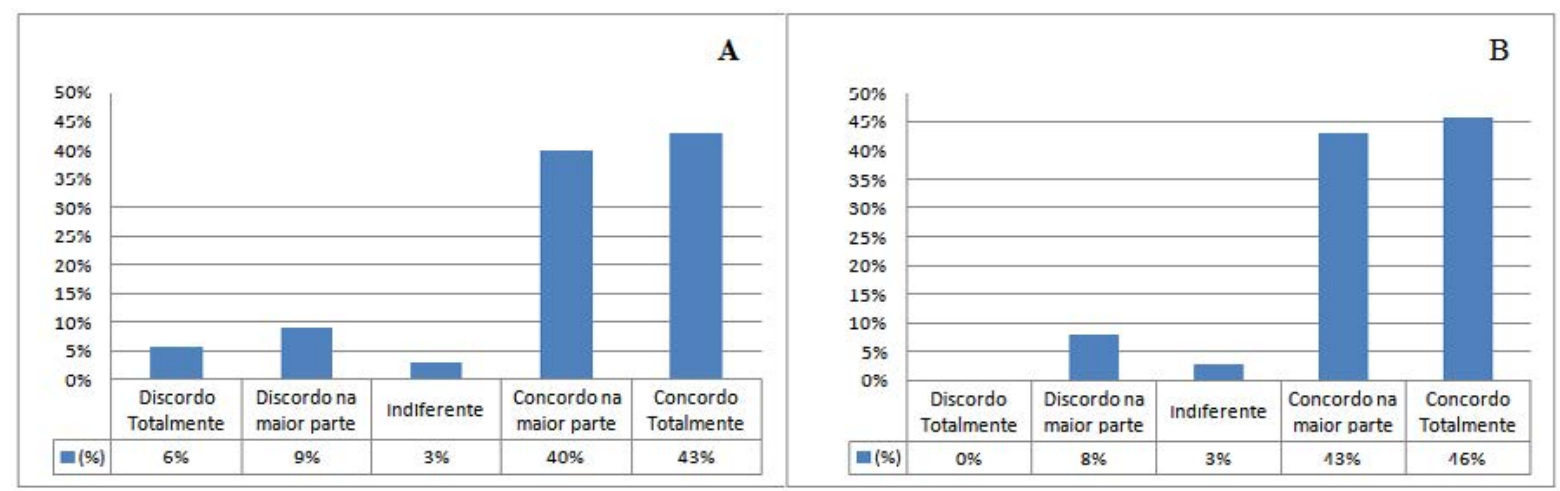


Mediante os resultados apresentados na Figura 10 (A), 43\% concordam totalmente que a organização recebe e reconhece suas opiniões, enquanto $9 \%$ discordam na maior parte e $6 \%$ discordam totalmente. Percebe-se assim, que essa realidade não é partilhada por todos, uma vez que, devido às respostas, apenas uma parte consegue colocar sua opinião de maneira a ser reconhecida dentro da empresa. Em consonância com o exposto, Chiavenato (2010) expõe que as pessoas passam a constituir o elemento básico do sucesso empresarial e que para isso necessitam ser ouvidas e valorizadas, contribuindo assim para um ambiente de trabalho favorável ao seu desenvolvimento.

Em análise da Figura 10 (B), segundo a abordagem feita pelos Gestores, foi apontado que existe liberdade para que os colaboradores possam opinar sobre o trabalho realizado, no qual $46 \%$ dos entrevistados concordam totalmente com essa questão e $8 \%$ discordam em parte. Segundo Gil (2001) é necessário também que a organização demonstre receptividade a todas as opiniões manifestadas, uma vez que estas podem ser utilizadas como um recurso para estreitamento das relações e melhoria do clima organizacional.

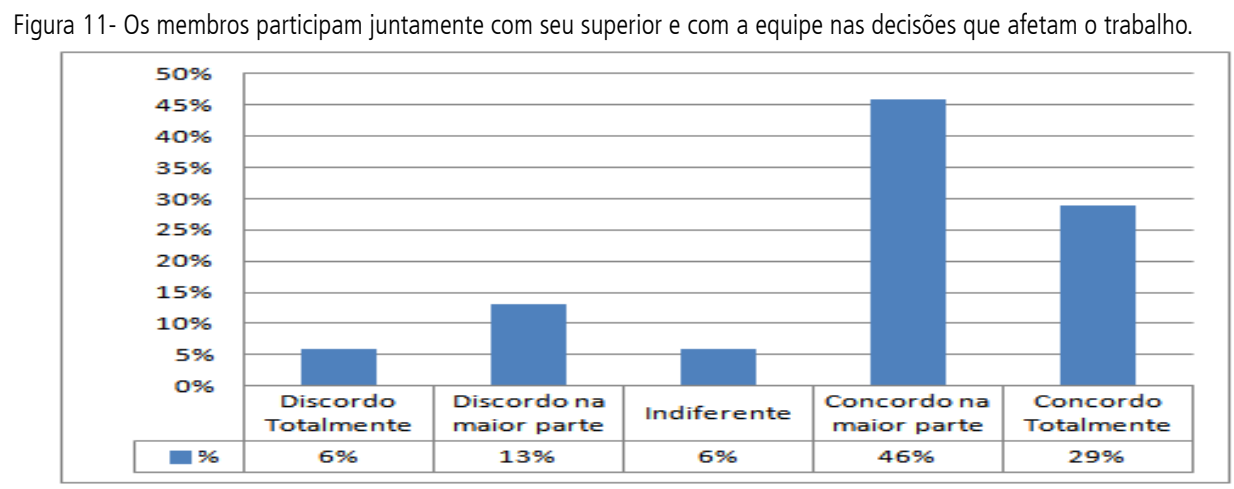

Quanto à participação dos colaboradores nas decisões juntamente com seu superior e a equipe da qual faz parte, na Figura 11 verificou-se que $46 \%$ dos respondentes concordam em parte quanto à participação e $6 \%$ discordam totalmente, ou seja, não participam do processo decisório, conforme apontado pelos gestores. Segundo Bonome (2009), a participação dos funcionários nas decisões da empresa, consiste basicamente na criação de oportunidades para que as pessoas influenciem nas decisões que as afetarão, valorizando assim, sua capacidade de tomada de decisões e solução de problemas, gerando maior motivação e satisfação que contribuem para a melhoria do clima organizacional.

Outro fator que influencia na satisfação e comprometimento dos colaboradores e consequentemente altera o clima organizacional é a remuneração. Para esse quesito, foi apontado pelos gestores que a empresa em foco remunera seus funcionários de acordo com a política de mercado - (A) e que a mesma está de acordo com as responsabilidades que cada um possui - (B), conforme Figura 12. 
Figura 12 - (A) Considero minha remuneração de acordo com a praticada no mercado - (B) Minha remuneração é compatível com as responsabilidades inerentes ao trabalho que realizo.

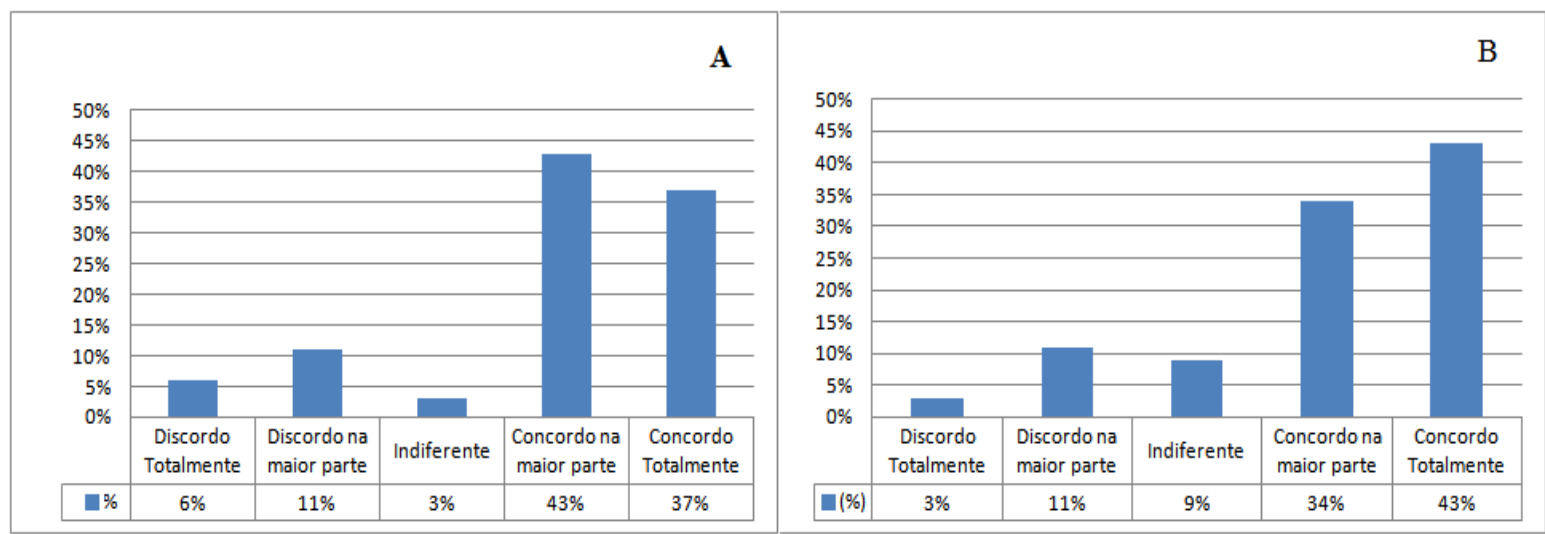

Conforme a análise da Figura 12 (A), 43\% consideram que sua remuneração está de acordo com a praticada no mercado, $11 \%$ discordam na maior parte e $6 \%$ discordam totalmente, indo ao contrário da assertiva apontada pelos gestores. Em síntese, a remuneração é fator motivacional, podendo gerar conflitos entre os membros de uma equipe quando apresentar alternâncias para uma mesma atividade realizada. Neste sentido, de acordo com a Figura 12 (B), 43\% concordam totalmente quanto a sua remuneração estar em consonância com as atividades desempenhadas, $11 \%$ discordam em partes e 3\% discordam totalmente.

Complementando, Wood Jr. (2011) explica que a modernização da gestão empresarial e adoção de novos modelos de organizações do trabalho obrigam os gestores a implantarem modelos de remuneração mais modernos, que atuem como uma ferramenta estratégica, favorecendo, não só os objetivos organizacionais, mas também os pessoais dos colaboradores.

No que tange o trabalho executado pelos colaboradores, foi apontado pelos Gestores, que os mesmos se sentem bem profissionalmente quando o estão executando. Neste sentido, esta questão foi adaptada e colocada da seguinte forma aos funcionários, conforme Figura 13: o trabalho que executo faz com que me sinta bem profissionalmente.

Figura 13 - 0 trabalho que executo faz com que me sinta bem profissionalmente.

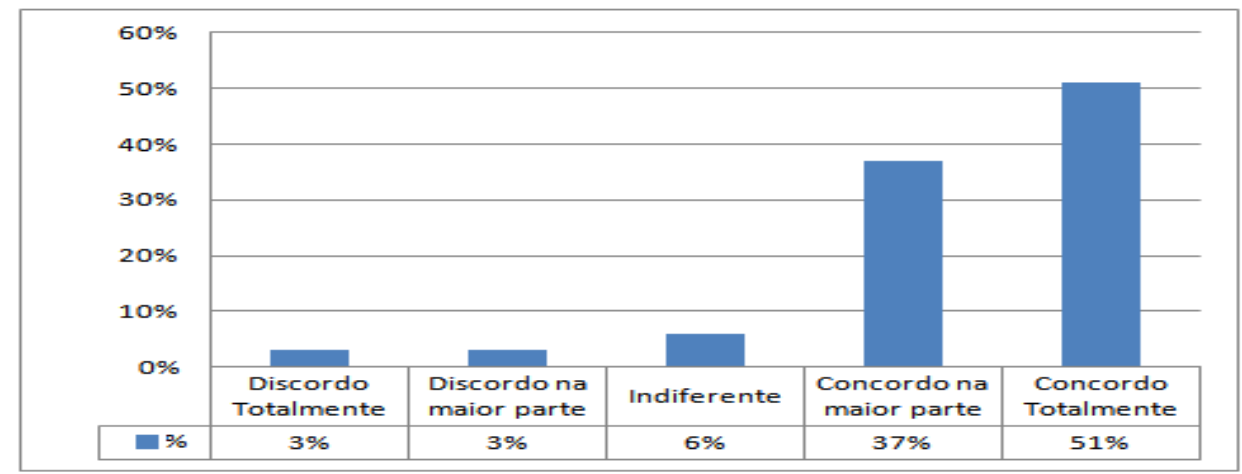


Conforme exposto na Figura 13, de todos os participantes, 51\% estão de pleno acordo e sentem-se bem profissionalmente com o trabalho que executam, enquanto do contrário, $3 \%$ discordam totalmente, ou seja, as atividades realizadas não fazem com que se sintam bem. Nesta perspectiva, quanto ao fato de não se sentir bem, faz com que o colaborador fique desmotivado, adotando um comportamento que impactará negativamente no clima organizacional. Segundo Mussak (2003), o colaborador motivado realiza qualquer atividade com mais qualidade e eficiência.

De acordo com Chiavenato (2010), o enriquecimento de tarefas, consiste em substituir tarefas mais simples e elementares do cargo, por outras mais complexas, acompanhando o crescimento de cada empregado, dando-lhe condições de desafio e de satisfação profissional. Para ele, o enriquecimento de tarefas traz efeitos altamente desejáveis, como aumento da motivação e da produtividade, redução do absenteísmo e a redução da rotatividade de pessoas, bem como a melhoria do clima organizacional.

Diante do exposto, indagou-se os colaboradores acerca da execução de suas atividades dentro do horário normal de trabalho, no qual essa questão foi primeiramente apresentada pelos gestores, teve como objetivo investigar se os mesmos conseguem realizar suas tarefas sem precisar fazer horas extras ou levar trabalho para a casa. Conforme Figura 14 abordou-se o seguinte: consigo executar as minhas tarefas diárias no horário normal de trabalho.

Figura 14 - Consigo executar as minhas tarefas diárias no horário normal de trabalho

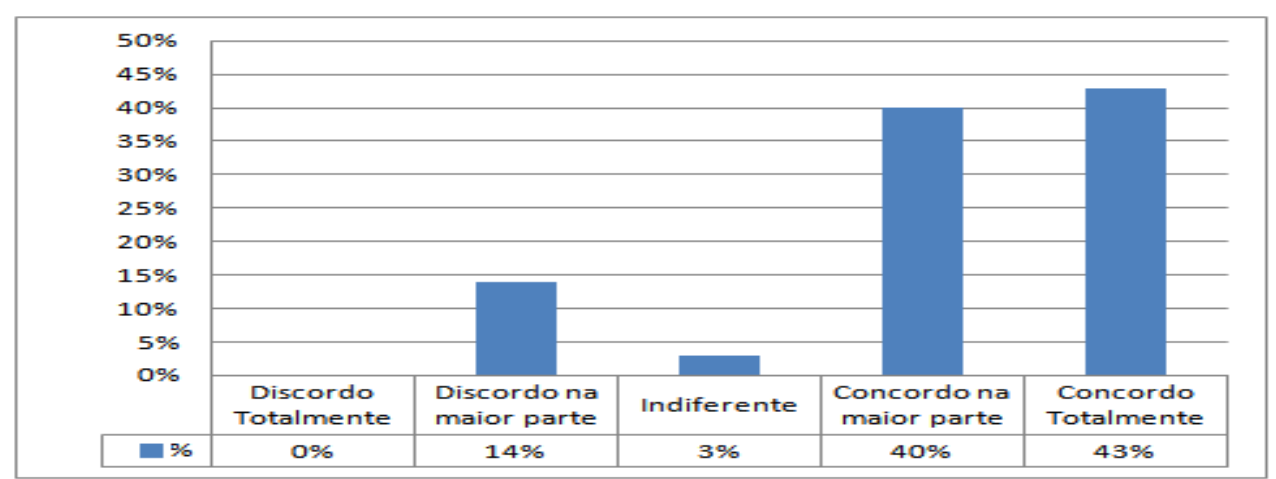

Analisando a Figura 14, percebe-se que $43 \%$ dos colaboradores concordam totalmente, apontando que conseguem executar suas tarefas no horário normal de trabalho, enquanto $14 \%$ discordam em partes, ou seja, nem sempre a execução de suas atividades ocorre de forma normal e dentro do mesmo período. Para, Brown et al. (2005) relacionam o tempo para execução das tarefas com a aprendizagem, alegando que seria bastante sensato que as empresas alocassem tempo para que os funcionários aprendam, em vez de ficarem constantemente ocupados.

Quanto às oportunidades de desenvolvimento dentro da organização, os gestores apontaram que todos os colaboradores as possuem, uma vez que, 
a maior parte destas oportunidades advém dos que administram a empresa, conforme colocada aos respondentes conforme Figura 15.

Figura 15 - Tenho oportunidade de desenvolvimento dentro da empresa.

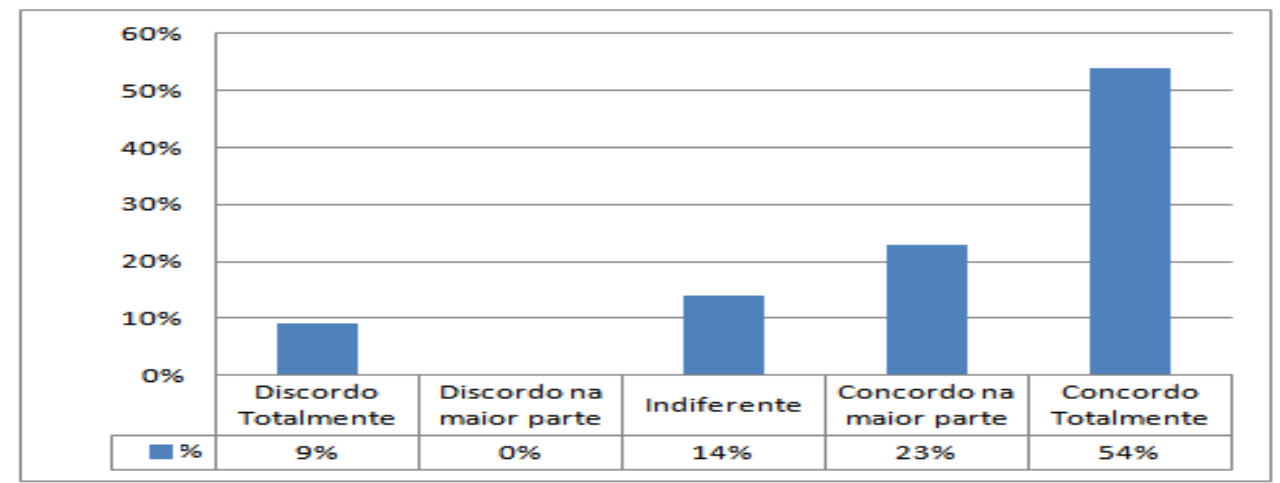

Percebe-se por meio da Figura 15 que 54\% possuem oportunidades dentro da empresa, pois concordaram totalmente com o que foi colocado pelos gestores enquanto $9 \%$ discordam totalmente. Vale salientar que as oportunidades de crescimento podem estar entrelaçadas ao comprometimento, individual e coletivo e que este pode motivar o funcionário, bem como aumentar sua produtividade. Chiavenato (2010) elucida que o desenvolvimento profissional é como a educação que visa ampliar, desenvolver e aperfeiçoar a pessoa para o seu crescimento profissional em determinada carreira na organização ou para que se torne mais eficiente e produtivo seu cargo. O crescimento profissional está ligado às visões e às oportunidades oferecidas pela organização, que contribui para o sucesso de seus colaboradores incentivando-os ao aprendizado constante.

Na Figura 16 abordou-se acerca da participação dos colaboradores nas atividades de integração que a empresa realiza, sendo que estas ações de socialização são importantes na promoção da integração e melhoria do clima organizacional. Silva et al. $(2008$, p. 12) ressaltam que um indivíduo socializado contribui com seu potencial intelectual, social e de trabalho para o alcance das metas da organização.

Figura 16 - Participo frequentemente das atividades de integração promovidas pela empresa

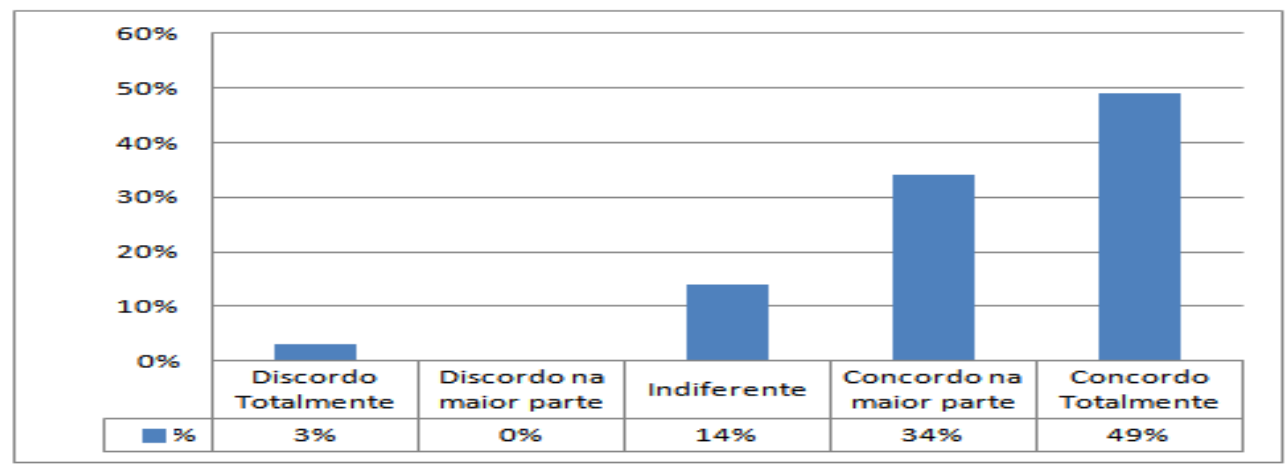


Analisando a Figura 16 percebe-se que $49 \%$ dos participantes são adeptos as atividades que a organização promove, enquanto $14 \%$ permaneceram indiferentes, ou seja, pode-se concluir que estas ações não tem representatividade para os mesmos. Chiavenato (2007) ressalta que as organizações necessitam criar ações estratégias voltadas à manutenção de boas relações humanas, através de ações que estimulem o desenvolvimento de um bom ambiente de trabalho, bem como políticas de integração, treinamento e aperfeiçoamento, nas quais sejam propostas ações voltadas à capacitação oportunidade de interação entre os membros do grupo e desenvolvimento profissional.

Em consonância com o exposto, na Figura 16 expõe-se a questão acerca da política de treinamento e aperfeiçoamento dos colaboradores, sendo este necessário para que possam desempenhar suas atividades de forma segura e com maior rapidez. Segundo Reginatto (2004), o treinamento ajuda as pessoas a serem mais eficientes, evitando erros, melhorando atitudes e alcançando maior produtividade, pois, aprende-se fazendo, reavaliando e mudando comportamentos.

Figura 17 - Existe política de treinamento e aperfeiçoamento dos funcionários.

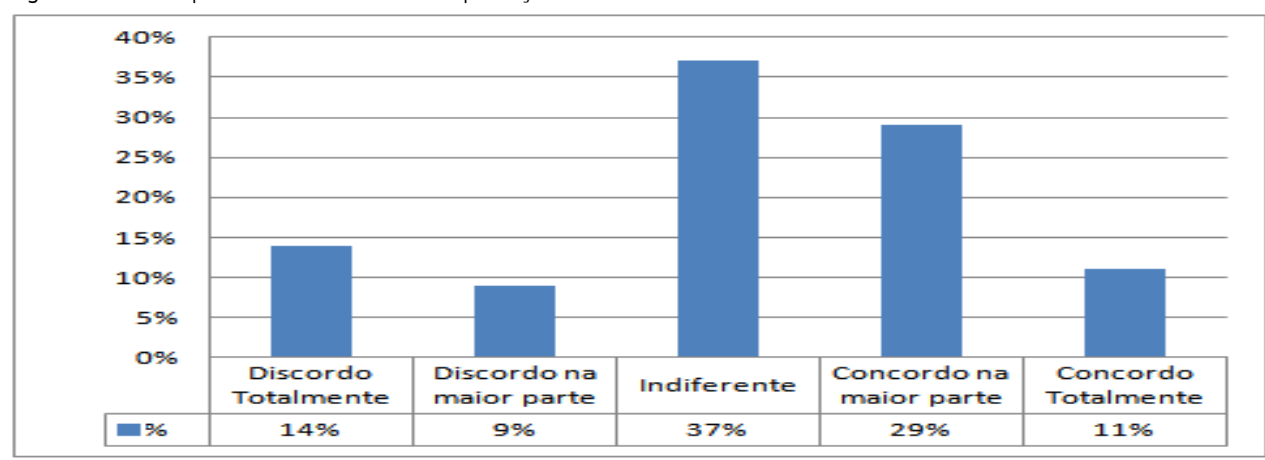

De acordo com o exposto na Figura 17, no que tange os treinamentos e aperfeiçoamento dos funcionários, os gestores apontam que existem políticas voltadas para esta questão, porém $37 \%$ dos entrevistados se mantiveram indiferente quanto a esta abordagem, $14 \%$ discordam totalmente e $9 \%$ discordam na maior parte. A ocorrência da maioria permanecerem indiferentes, pode ser devido ao fato de temerem a perda do emprego, o que devido às outras respostas, percebe-se que na visão dos colaboradores a parte de treinamentos dentro da organização não atende as expectativas apontadas.

Segundo Julião e Vandi (2008), as consultas sobre as necessidades de treinamento devem ser contínuas e permanentes, e caracterizam-se por ser o primeiro passo na organização de um treinamento; entendendo a necessidade como situações que devem ser mantidas ou atingidas para o alcance de um objetivo.

Percebe-se assim, que inúmeros são os fatores que influenciam no clima organizacional e que por vezes são influenciados também. Neste estudo, a realidade assegurada pelos gestores, não obteve sua totalidade frente às respostas dos colaboradores, notando-se assim que dentro da organização 
existem funcionários desmotivados, com a liderança, clima organizacional, relações com os colegas, cargos e salários, o que gera um comportamento inseguro frente às atividades desenvolvidas. O desconhecimento do clima organizacional, por parte dos gestores, compromete o ambiente de trabalho, mascarando as ações que necessitam serem efetivadas para que a realidade apresentada mude.

\section{Considerações finais}

A avaliação do clima organizacional tem sido percebida por muitas organizações como uma aliada na busca de alternativas que mensurem a influência das variáveis organizacionais, individuais e sociais, no desempenho dos colaboradores. Há de certa forma, alguns fatores que corroboram para um ambiente saudável, permitindo a integração do indivíduo com o meio em que desenvolve suas atividades.

Mediante o objetivo do presente estudo, que foi analisar as percepções dos gestores e colaboradores do setor administrativo em relação ao clima organizacional, percebeu-se a necessidade de um envolvimento maior por parte da gerência para com os funcionários. Assim, ao conhecer a realidade que a empresa se encontra, torna-se possível perceber o que devem incentivar para promover a realização e o bem-estar dos colaboradores, por meio de ações que possibilite um clima organizacional acolhedor a todos os tipos de comportamentos individuais e coletivos.

Partindo disto, averiguou-se também, que nem sempre é possível agradar a todos dentro da organização, pois ao mesmo tempo em que os colaboradores são influenciados pelo clima organizacional, acabam influenciando-o também. Nesta conjuntura, o perfil individual do colaborador exerce, também, influência na sua realização profissional, pois o seu comportamento dentro do ambiente de trabalho funciona como mediador nas relações interpessoais. Logo, o clima organizacional exerce um papel importante na realização profissional do trabalhador, refletindo num maior comprometimento para com a organização.

Em síntese, apesar de uma avaliação do clima favorável por parte dos colaboradores, perceberam-se algumas divergências entre as colocações dos gestores e o respondido pelos colaboradores no questionário aplicado. Com isso, sugere-se à gerência da organização uma gestão mais participativa, que favoreça o desenvolvimento pessoal e profissional dos colaboradores, aumentando a qualidade das informações e permitindo-os uma maior participação no processo decisório.

Como sugestão, propõe-se a criação de um departamento voltado para atender as necessidades dos colaboradores, bem como na promoção de atividades integradoras, o qual poderá auxiliar a empresa na construção de um ambiente mais dinâmico e inclusivo, pois, partindo da premissa de que um bom clima organizacional necessita de ações específicas para acontecer, 
uma delas deve estar pautada no enlace entre os objetivos individuais das pessoas com os organizacionais, resultando em um melhor desempenho organizacional, advindo pela realização pessoal e profissional dos envolvidos na empresa, sejam colaboradores ou gerência.

Por fim, as limitações encontradas mediante a realização da pesquisa são de caráter de abrangência, pois, levando em consideração que a empresa possui filiais em várias partes do Brasil, não foi possível aplicar o questionário aos demais colaboradores, além de que, os que se encontravam no setor onde foi realizada, nem todos se propuseram a participar. Para estudos futuros, sugere-se ampliar a amostra de respondentes dos questionários, bem como fazer uma análise comparativa entre as respostas dos dois grupos participantes. 


\section{Referências}

ABZARI, M.; ABBASI, R. Investigating Impact of Organizational Climate on Intention to knowledge Sharing Behavior by Using Theory of Planned Behavior (TPB). Interdisciplinary journal of contemporary research in business, v. 2, n. 12, p. 121-134, 2011.

ARGYLE, M. Psicología del comportamiento interpersonal. Madrid: Alianza Editorial, 1994.

BERGAMINI, C. W. Psicologia aplicada à administração de empresas: psicologia do comportamento organizacional. São Paulo: Atlas, 2006.

BOHLANDER, G.; SNELL, S. Administração de recursos humanos. São Paulo: Cengage Learning, 2009.

BONOME, J.B.V. Teoria Geral da Administração. Curitiba IESDE Brasil S. A, 2009.

BROWN, S. et al. Administração da Produção e Operações: Um enfoque estratégico na manufatura e nos serviços. Rio de Janeiro: Elzevier, 2005.

CALDERÓN, G.; NARANJO, J. C.; ÁLVAREZ, C. M. La gestión humana en Colombia: características y tendencias de la práctica y de la investigación. Estudios Gerenciales, v. 23, n. 103, p. 39-64, 2007.

CARDENAS, L.; ARCINIEGAS, Y. C.; BARRERA, M. (2009). Modelo de intervención en clima organizacional. International Journal of Psychological Research, v. 2, n. 2, p. 121- 127, 2009.

CARMELI, A.; DUTTON, J. E.; HARDIN, A. E.; Respect as an engine for new ideas: Linking respectful engagement, relational information processing and creativity among employees and teams. Humans Reations, v. 68 , n. 8. p. 1315-1346, 2015.

CARVALHAL, E.; ANDRÉ NETO, A.; ANDRADE, G. Negociação e administração de conflitos. Rio de Janeiro: FGV, 2006.

CARVALHO, C. A. Poder, conflito e controle nas organizações modernas. Maceió: Edufal, 1998.

CARVALHO, C. A.; VIEIRA, M. M. F. O poder nas organizações. São Paulo: Thomson Learning, 2007.

CAUCHICK MIGUEL, P. A. et al. Metodologia de Pesquisa em Engenharia da Produção e Gestão de Operações. $2^{\circ}$ Ed. Rio de Janeiro: Elsevier : ABEPRO, 2012.

CHAMBEL, M. J.; CURRAL, L. Psicologia organizacional: Da estrutura à cultura. Lisboa: Livros Horizonte, 2008.

CHIANG, M.; NÚÑEZ, A. Adaptación y ampliación de un instrumento para medir clima organizacional, satisfacción laboral y autoeficacia en grupos de trabajo. Revista De Estudios Sociales, v. 115, p. 111-139, 2005

CHIAVENATO, I. Administração de recursos humanos: fundamentos básicos. 2ª Edição. São Paulo: Atlas, 2007.

Gestão de Pessoas. 3. ed. rev. e atual. - Rio de Janeiro: Elsevier, 2010.

CHRISPINO, A. Gestão do conflito escolar: da classificação dos conflitos aos modelos de mediação. Ensaio: Avaliação e Políticas Públicas em Educação, v. 15, n. 54, p. 11- 28, 2007.

COLLIS, J.; HUSSEY, R. Pesquisa em Administração: um guia pratico para alunos da graduação. $2^{\circ}$ Ed. Porto Alegre: Bookman, 2005.

COSTA, J. Mensuração e desenvolvimento de escalas: aplicações em administração. Rio de Janeiro: Ciência Moderna, 2011.

DAVILA, T.; WOUTERS, M. Managing budget emphasis through the explicit design of conditional budgetary slack. Accounting, Organizations and Society, v. 30, n. 7-8, p. 587-608, 2005.

ECHEVARRÍA D. Cultura organizacional y estilos de dirección desde la perspectiva de género: desafíos de la empresa Cubana. La Habana, 2007.

ECHEVERRI, D. R.; CRUZ, R. Revisión de instrumentos de evaluación de clima organizacional. Estudios Gerenciales, V. 30, n. 131, p. 184-189, 2014.

FAURÉ, B.; ROULEAU, L. The strategic competence of accountants and middle managers in budget making. Accounting, Organizations and Society, v. 36, n. 3, p. 167-182, 2011.

FERREIRA, V. C. P.; FORTUNA, A. A. M.; TACHIZAWA, T. 2006. Gestão com Pessoas. FGV: Rio de Janeiro, 2006. 
GIL, A. C. Gestão de Pessoas. São Paulo: 2001.

GOHEL, K. Psychological capital as a determinant of employee satisfaction. International Referred Research Journal, v. 3, n. 36, p. 34-37, 2012.

GUILLÉN M. Clima organizacional en la Editorial Ciencias Médicas a partir del análisis de dos de sus dimensiones. Rev Cubana Salud Pública, v. 39, n. 2, p. 242-252, 2013.

GUILLÉN, G.; GALA, L,; VELÁZQUEZ, M. Clima organizacional. Psicología del trabajo para relaciones laborales. México. Mc. Graw Hill, 2000.

GUILLÉN, I. J.; ADUNA, A. P. (2008). La influencia de la cultura y del estilo de gestión sobre el clima organizacional. Estudio de caso de la mediana empresa en la delegación Iztapalapa. Estudios Gerenciales, v. 24, n. 106, p. 47-64, 2008.

HELLRIEGEL, D. y SOLOCUM, J. W. Organizational climate: Measures, research and contingencies. Academy of Management Journal, v. 17, p. 255-280, 1974.

JARAMILLO, O. Mercado laboral de los profesionales de la información em Colombia: resultados del análisis de las ofertas de empleo. Medellín: Universidad de Antioquia, 2013.

JULIÃO, B. E.; VANDI, A. M. Diferenças entre treinamento, desenvolvimento e aprendizagem. Grupo de estudo em ABRH, 2008. <Disponivel em: http://www.abrhrs.com.br/2008/grupos-artigos-mostrar. php?cod=101>. Acesso em: 24 out. 2015.

KOPELMAN, R. E. et al. The Role of Climate and Culture in Productivity. In B. Schneider (Ed.), Organizational climate and culture. San Francisco, CA: Jossey-Bass, 1990.

LEITÃO, S. P.; FORTUNATO, G.; FREITAS, A. S. Relacionamentos interpessoais e emoções nas organizações: uma visão biológica. Revista de Administração Pública. Print version, 2006.

LI, Z.; ZHU, T.; LUO, F. A Study on the Influence of Organizational Climate on Knowledge-Sharing Behavior in IT Enterprises. Journal of Computers, v. 5, n. 4, p. 508-515, 2010.

LUTHANS, F.; NORMAN, S. M.; AVOLIO, B. J.; AVEY, J. B. The mediating role of psychological capital in the supportive organizational climate employee performance relationship. Journal of Organizational Behavior, v. 29, n. 2, p. 219-238, 2008.

MADARIAGA, M. G. Comunicación y liderazgo: sin comunicación no hay líder. Cuadernos del Centro de Estudios en Diseño y Comunicación, n. 33, p. 61-72, 2010.

MALHOTRA, N. K. Pesquisa de Marketing: uma orientação aplicada. Porto Alegre: Bookman. 2012.

MCINTYRE, S. E. Como as pessoas gerem o conflito nas organizações: estratégias individuais negociais. Análise Psicológica, Lisboa, v. 25, n. 2, p. 295-305, 2007.

MÉNDEZ, C. Clima organizacional en colombia. El imcoc: un método de análisis para su intervención. Colección de lecciones en administración. Bogotá, universidad del rosário, 2006.

MOOS, R. H. Conceptualizations of human environments. American Psychologist, v. 28, p. 652-665, 1973.

MORONI L.; DABOS G. E. Comportamientos abusivos de baja intensidad en las organizaciones: una revisión de la literatura y de sus implicâncias. Estudios Gerenciales, v. 30, p. 384-396, 2014.

MOTTA, P. R. Gestão contemporânea: a ciência e a arte de ser dirigente. 15. ed. Rio de Janeiro: Record, 2004.

MULLINS, L. J. Gestão da hospitalidade e comportamento organizacional. 4 ed. Porto Alegre: Bookman, 2004.

MUSSAK, E. Metacompetência: uma nova visão do trabalho e da realização pessoal. $2^{a}$ ed. São Paulo: Gente, 2003.

NEVES, J. G. Clima Organizacional, cultura Organizacional e gestão de recursos humanos. Lisboa: Editora RH. 2000.

NORIEGA V. Otra aproximación al estudio del clima organizacional. Revista Infodir, v. 13, n. 9, 2009.

NORIEGA V.; PRIA M. Instrumento para evaluar el clima organizacional en los Grupos de Control de Vectores. Rev Cubana Salud Pública, v. 378, n. 2, 2011.

OTLEY, D. T. Budget use and managerial performance. Journal of Accounting Research, v. 16, n. 1, p. 122-149, 1978. 
PARKER, M. Organizational culture and identity. London: SAGE Publications, 2003.

PÉREZ, I.; MALDONADO, M.; PÉREZ M.; BUSTAMANTE, S. Clima organizacional y gerencia: inductores del cambio organizacional. Investigación y Postgrado. v. 21, n. 2, p. 231-248, 2006.

QUINN, R. E. et al. Competências Gerenciais: princípios e aplicações. Rio de Janeiro: Elsevier, 2003.

REGINATTO, A. P. Equipes campeãs: potencializando o desempenho de sua equipe. 2. ed. Porto Alegre : SEBRAE/ RS, 2004.

REYES, M. M.; ZAPATA, D. I. Relation Between Organizational Climate and its Dimensions and Knowledge-sharing Behavior among Knowledge Workers. int.j.psychol.res, v. 7, n. 2, p. 64-75, 2014

ROBBINS, S. P.; JUDGE; T. A.; SOBRAL, F. Comportamento Organizacional. 14ª ed. São Paulo: Pearson Prentice Hall, 2010.

ROBERTS, J. The possibilities of accountability. Accounting, Organizations and Society, v. 16, n. 4, p. 355-368, 1991.

RUPERTI, C. Comunicación Organizacional y Relaciones Públicas. Retrieved from, 2009.

SANTANA, P.; ARAUJO, Y. Clima y cultura organizacional: ¿dos constructos para explicar un mismo fenómeno? En: Asociación Europea de Dirección y Economía, 2007.

SCHNEIDER, B,; EHRHART, M. G,; MACEY, W. A. Perspectives on organizational climate and culture. In: Zedeck $S$, editor. APA handbook of industrial and organizational psychology; Vol. 1. Building and developing the organization. Washington, DC: American Psychological Association, p. 373-414, 2011.

SILVA, A. D. et al. Estratégias de Socialização: a forma mais eficaz para a integração entre indivíduo e organização. In: Simpósio de Excelência em Gestão e Tecnologia. Anais... V SEGET, Resende, 2008.

SILVA, L.G.; MATSUDA, L.M.; WAIDMAN, M.A.P. A estrutura de um serviço de urgência público, na ótica dos trabalhadores: perspectivas da qualidade. Texto Contexto Enfermagem, v. 21, n. 2, p. 302-328, 2012.

SOUZA, T. A.; CAMPOS, J.; DEJANIR, J.; MAGALHÃES, S. R. A importância do clima organizacional. Revista da Universidade Vale do Rio Verde, v. 13, n.1, p. 315-329, 2015.

SWIFT, P. E.; HWANG, A. Learning, dynamic capabilities and operating routines: A consumer package goods company. The Learning Organization, v. 15, n. 1, p.75-95, 2008.

TAMAYO, A. Impacto dos valores pessoais e organizacionais sobre o comprometimento organizacional. In: TAMAYO, A.; PORTO, J. B. (Ed.). Valores e comportamento nas organizações. Rio de Janeiro: Vozes, 2005. p. 160-186, 2005.

SOUZA, T. A.; CAMPOS JÚNIOR, D. J.; MAGALHÃES, S. R. A importância do clima organizacional. Revista da Universidade Vale do Rio Verde, v. 13, n. 1, p. 315-329, 2015.

TOMAÉL, M. I.; ALCARÁ, A. R.; DI CHIARA, I. G. Das redes sociais à inovação. Ci. Inf., Brasília, v. 34, n. 2, p. 93104, 2005.

TORMO, G.; OSCA, A. Antecedentes Organizacionales y Personales de las Intenciones de Compartir Conocimiento: Apoyo, Clima y Compromiso con la Organización. Revista de Psicología del Trabajo y de las Organizaciones, v. 27, n. 3, p. 213- 226, 2011.

UCYMAT - Dirección del Trabajo. Problemas actuales en salud de los trabajadores. Santiago: LOM. Ediciones, 2001.

VALLEJO, J. La personalidad integradora: El doble logro de ser sí mismo y vincularse. Barcelona: Ediciones CEDEL, 2004.

VENDEMIATTI, M. et al. Conflito na gestão hospitalar: o papel da liderança. Revista Ciência e Saúde Coletiva, v. 15, n. 1, p. 1301-1314, 2010.

WOOD JR. T. Remuneração Estratégica. São Paulo: Atlas, 2011.

ZUTTA, M. Estilo de dirección. Equipo Operativo MECI-SGC. San Juan de Pasto, Colombia, 2008. 